\title{
Review of CIGRE TB 496 regarding Prequalification Test on Extruded MVDC Cables
}

\author{
A. Buchner \& U. Schichler \\ Institute of High Voltage Engineering and System Performance, Graz University of Technology, Graz, Austria \\ anton.buchner@tugraz.at
}

\begin{abstract}
The well established HVDC power transmission technology is currently also seen as a viable solution for the medium-voltage range and there is a growing demand for extruded MVDC cables. The CIGRE TB 496 gives recommendations for highvoltage tests on extruded DC cable systems with rated voltage up to $500 \mathrm{kV}$, but do not consider the technical differences between HVDC and MVDC cables. Therefore, the prequalification test described in CIGRE TB 496 is analysed and an optimised PQ test is proposed for extruded MVDC cables.
\end{abstract}

\section{Introduction}

The growing use of renewable energy sources leads to the need of long-distance high-capacity transmission lines. With the technical, operational, and economic restrictions (e. g. charging current, skin effect, cost), the maximum transmission length and efficiency of AC lines is limited. Therefore, the application of High-Voltage Direct Current (HVDC) power transmission is becoming widespread, especially in Europe and China.

HVDC cables, in particular, play an important role in submarine power transmission and offshore renewable energy integration having lower losses and higher reliability. Also onshore grids will be increasingly enforced by DC cables [1 - 3]. Since the end of the 1990s, extruded DC cables with polymeric insulation have been in use, which show environmental benefits in comparison with oil-filled and mass-impregnated DC cables.

The well established HVDC power transmission technology is currently also seen as a viable solution for the medium-voltage range and there is a growing demand for extruded MVDC cables. The refurbishing of existing MVAC cables resp. the application of new MVAC XLPE cables for DC operation is under discussion [4 - 8].

The CIGRE Technical Brochure No. 496 gives recommendations for type test and prequalification test (PQ test) on extruded DC cable systems with rated voltage up to $500 \mathrm{kV}$, but do not consider the technical differences between HVDC and MVDC cables [9].

MVDC cables generally have the same design as HVDC cables, but there are differences with respect to conductor crosssection, insulation thickness, insulation material and electric field stress during operation and testing. Therefore, in this report the prequalification test described in CIGRE TB 496 is analysed and an optimised PQ test is proposed for extruded MVDC cables, which is based on experimental investigations and data from literature.

\section{Success story of extruded DC cables}

DC cables have been used mainly in the form of paperinsulated submarine cables (OF, MI, PPLP) for transporting energy over long distances. Since the end of the 1990s, extruded DC cables with PE/XLPE insulation have also been in use, which are currently used with DC voltages of up to $320 \mathrm{kV}$ and are commercially available for $525 \mathrm{kV}$ [1 - 3]. Extruded DC cables for $640 \mathrm{kV}$ are fully developed and have passed the required tests [10]. The previous success story of extruded DC cables can be traced back to the following HVDC projects [1, 3].

- The first HVDC project with XLPE insulated DC cables was commissioned in 1999 with a transmission capacity of $50 \mathrm{MW}$ and a length of $72 \mathrm{~km}$ ("Gotland Link" project). It is a bipolar $80 \mathrm{kV}$ DC cable system with an insulation thickness of $5.5 \mathrm{~mm}$.

- Another important milestone was the commissioning of the 400 MW HVDC project "Trans Bay" in San Francisco in 2010. The $200 \mathrm{kV}$ DC cables used for the first time worldwide have a copper conductor with a conductor cross-section of $1,100 \mathrm{~mm}^{2}$.

- An XLPE DC cable system with a rated voltage of $320 \mathrm{kV}$ and a transmission capacity of $800 \mathrm{MW}$ was used for the first time in the HVDC project "DolWin 1". The transmission line has a length of $165 \mathrm{~km}$ and was commissioned in 2014 .

- The German onshore EHV grid shall be enforced by $525 \mathrm{kV}$ DC cable systems. The cables shall have a conductor crosssection of 2,500 $\mathrm{mm}^{2}$ or more and an insulation thickness of at least $26 \mathrm{~mm}$. A transmission capacity of $2 \mathrm{GW}$ is planned for a bipolar DC cable system.

Testing of extruded DC cables was described first in 2003 for rated voltages up to $250 \mathrm{kV}$ by CIGRE TB 219 and - due to technical progress - updated in 2012 for rated voltages up to $500 \mathrm{kV}$ by CIGRE TB $496[9,11]$. IEC 62895 was published in 2017 based on CIGRE TB 496 and limited to land cables up to $320 \mathrm{kV}$ [12]. Currently CIGRE WG B1.62 is discussing the testing of DC cable systems up to $800 \mathrm{kV}$. It should be noted that today's high-voltage testing of extruded DC cables follows the recommendations of CIGRE TB 496 and the main focus is on the prequalification test (PQ test) with a test duration of 1 year.

The recent demand on MVDC cables can be seen by an increasing number of publications. The refurbishing of existing MVAC cables resp. the application of new MVAC XLPE cables for DC operation is under discussion [4 - 8]. In this context, it is a clear benefit that today's MVAC XLPE cable technology is accompanied by a stable and voluminous supply chain and wellstandardised quality assurance methods. 


\section{Phenomena in DC Cables}

The electric field distribution at DC voltage is determined by the conductivity, which has a strong dependency on temperature and electric field strength. This leads to several technical effects that do not occur under AC stress [1,2].

Field inversion: The electric field distribution in a DC cable depends on the temperature and electric field strength dependent conductivity of the insulation material used. A temperature gradient $\Delta \mathrm{T}$ in the cable insulation caused by the current heat losses of the cable conductor leads to a reduction in the electric field strength on the inner conductor and to an increase in the field strength on the outer conductor.

Accumulation of space charges: Polymer insulating materials such as XLPE are able to store free charge carriers. The resulting temperature-, field strength-, time- and locationdependent accumulation of space charges influence the electric field distribution in the cable insulation and can lead to failures especially after a polarity reversal. The measurement of space charges in thin material samples and thick-walled cable insulations can be carried out experimentally using various methods (PEA, TSM). With suitable measures and modifications of the insulating material, it is possible to minimize the space charge formation.

Thermal runaway: The temperature-dependent conductivity of the insulation material can lead to low insulation resistance at high temperatures. This results in an increased direct current through the cable insulation and a related further heating of the dielectric. This continuously progressive heating leads to a thermal breakdown of the cable dielectric. In the past, the described effect limits the maximum conductor temperature for XLPE insulated DC cables to $70{ }^{\circ} \mathrm{C}$ and is excluded for modern extruded DC cables by appropriately selected and modified insulation materials.

\section{PQ test according CIGRE TB 496}

The prequalification test is intended to indicate the long-term performance of a complete cable system. It consists of a long duration voltage test with a minimum duration of 360 days and a superimposed impulse voltage test. The sequence of tests for LCC and VSC are different (Table 1, Table 2) and the conditions can be described as follows $\left(\mathrm{U}_{0}=\right.$ rated $\mathrm{DC}$ voltage $)$ :

LC: The DC test voltage at a load cycle is kept constant at $\mathrm{U}_{\mathrm{TP} 1}=1.45 \times \mathrm{U}_{0}$ whereas the tested cable system is heated up by an appropriate conductor current for 8 hours followed by a cool down period of 16 hours. The applied heating current shall be set to reach the maximum conductor temperature as well as the maximum temperature difference across the insulation for at least the last two hours of the heating period.

LC + PR: At a load cycle with polarity reversals the polarity of the DC test voltage $\mathrm{U}_{\mathrm{TP} 2}=1.25 \times \mathrm{U}_{0}$ is changed every 8 hours, whereas the tested cable system is heated with $8 / 16$ hours heating cycles as described above.

HL: During high load, the heating current as well as the DC test voltage $\mathrm{U}_{\mathrm{TP} 1}$ are kept constant.
ZL: During zero load, no heating is applied whereas the DC test voltage $\mathrm{U}_{\mathrm{TP} 1}$ is kept constant.

S/IMP: To check the integrity of the insulation system a final test with superimposed voltages (DC/SI, optional: DC/LI) has to be performed. The test parameters are defined as $\mathrm{U}_{\mathrm{P} 2, \mathrm{O}}=1.2 \times \mathrm{U}_{0}$ respectively $\mathrm{U}_{\mathrm{P} 1}=2.1 \times \mathrm{U}_{0}$. Previous to the impulse stress the tested cable system shall be conditioned for at least 10 hours with $\mathrm{U}_{0}$ of the corresponding polarity as well as an appropriate heating current. Each impulse polarity shall be applied 10 times. The complex high-voltage test setup according to IEC 60060-1 (Figure 1) consists of two voltage generators, additional electric protection elements and a voltage measurement directly at the test object with a universal voltage divider $[13,14]$.

Table 1. Sequence of tests for LCC

\begin{tabular}{|c|c|c|c|c|}
\hline No. & Test & $\begin{array}{c}\text { No. of } \\
\text { cycles/days }\end{array}$ & Polarity & $\begin{array}{c}\text { Test } \\
\text { voltage }\end{array}$ \\
\hline 1 & LC & 30 cycles & + & $\mathrm{U}_{\mathrm{TP} 1}$ \\
\hline 2 & LC & 30 cycles & - & UTP1 \\
\hline 3 & $\mathrm{LC}+\mathrm{PR}$ & 20 cycles & \pm & $\mathrm{UTP}_{\mathrm{TP}}$ \\
\hline 4 & HL & 40 days & + & $\mathrm{U}_{\mathrm{TP} 1}$ \\
\hline 5 & $\mathrm{HL}$ & 40 days & - & UTP1 \\
\hline 6 & ZL & 120 days & - & $\mathrm{U}_{\mathrm{TP} 1}$ \\
\hline 7 & $\mathrm{LC}$ & 30 cycles & + & $\mathrm{U}_{\mathrm{TP} 1}$ \\
\hline 8 & $\mathrm{LC}$ & 30 cycles & - & $\mathrm{U}_{\mathrm{TP} 1}$ \\
\hline 9 & $\mathrm{LC}+\mathrm{PR}$ & 20 cycles & \pm & UTP2 \\
\hline 10 & S/IMP & --- & bipolar & $\mathrm{U}_{\mathrm{P} 2, \mathrm{O} / \mathrm{U}_{\mathrm{P} 1}}$ \\
\hline
\end{tabular}

Table 2. Sequence of tests for VSC

\begin{tabular}{|c|c|c|c|c|}
\hline No. & Test & $\begin{array}{c}\text { No. of } \\
\text { cycles/days }\end{array}$ & Polarity & $\begin{array}{c}\text { Test } \\
\text { voltage }\end{array}$ \\
\hline 1 & $\mathrm{LC}$ & 40 cycles & + & $\mathrm{U}_{\mathrm{TP} 1}$ \\
\hline 2 & $\mathrm{LC}$ & 40 cycles & - & $\mathrm{UTP}_{\mathrm{T} 1}$ \\
\hline 3 & $\mathrm{HL}$ & 40 days & + & $\mathrm{U}_{\mathrm{TP} 1}$ \\
\hline 4 & $\mathrm{HL}$ & 40 days & - & $\mathrm{U}_{\mathrm{TP} 1}$ \\
\hline 5 & ZL & 120 days & - & $\mathrm{U}_{\mathrm{TP} 1}$ \\
\hline 6 & $\mathrm{LC}$ & 40 cycles & + & $\mathrm{UTP}_{\mathrm{TP}}$ \\
\hline 7 & $\mathrm{LC}$ & 40 cycles & - & $\mathrm{U}_{\mathrm{TP} 1}$ \\
\hline 8 & S/IMP & --- & bipolar & $\mathrm{UP}_{2, \mathrm{O}} / \mathrm{UP}_{\mathrm{P}}$ \\
\hline
\end{tabular}

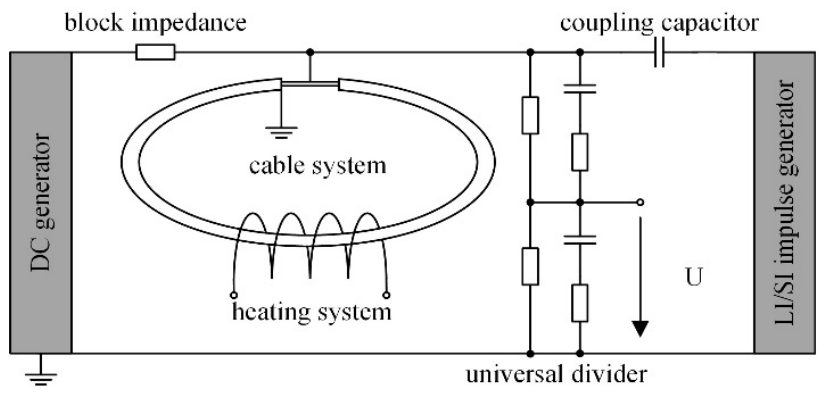

Figure 1. HV test setup for superimposed voltage test 


\section{Comparision of cables for MVDC and HVDC}

MVDC cables generally have the same design as HVDC cables. The main differences, however, are conductor crosssection, insulation thickness, insulation material and electric field stress during operation and testing. Table 3 is summarizing the main parameters for MVDC and HVDC cables.

In this context it should be mentioned that in medium-term the insulation material for MVDC cables will be XLPE and most likely AC XLPE resp. MVAC XLPE cables will be used for certain MVDC applications.

Table 3. Comparison of extruded cables for MVDC and HVDC by consideration of generally available data

\begin{tabular}{|c|c|c|}
\hline Parameter & MVDC & HVDC \\
\hline \hline rated voltage & $10-50 \mathrm{kV}$ & $80-525(640) \mathrm{kV}$ \\
\hline $\begin{array}{c}\text { conductor cross- } \\
\text { section }\end{array}$ & $95-630 \mathrm{~mm}^{2}$ & up to $3,000 \mathrm{~mm}^{2}$ \\
\hline $\begin{array}{c}\text { insulation } \\
\text { thickness }\end{array}$ & $\begin{array}{c}3.4,5.5,8.0 \mathrm{~mm} \\
\text { (based on MVAC cables) }\end{array}$ & $5.5-26 \mathrm{~mm}$ \\
\hline $\begin{array}{c}\text { mean field stress } \\
\text { in service }\end{array}$ & $10 \mathrm{kV} / \mathrm{mm}$ & $20 \mathrm{kV} / \mathrm{mm}$ \\
\hline $\begin{array}{c}\text { insulation } \\
\text { material }\end{array}$ & XLPE & $\begin{array}{c}\text { PE, XLPE, PP } \\
\text { (pure or modified) }\end{array}$ \\
\hline $\begin{array}{c}\text { converter } \\
\text { technology }\end{array}$ & LCC, VSC & (LCC) VSC \\
\hline
\end{tabular}

\section{Experiment: PQ test on a MVAC cable}

For the prequalification test, the test setup was made of two cable loops with a length of 10 meters each. The cables were combined with $12 / 20 \mathrm{kV}$ outdoor slip-on terminations with geometrical field control and one cable loop was additionally equipped with a $12 / 20 \mathrm{kV}$ heat-shrinkable joint with refractive field control. Both test loops were combined to a 20 meter long test setup and used for experiments according to CIGRE TB 496. The tested cable was a new standard $12 / 20 \mathrm{kV}$ AC XLPE cable (NA2XS(F)2Y 1x150RM/25) with an insulation thickness of $\mathrm{S}=5.5 \mathrm{~mm}$. As a result of preliminary tests with impulse and superimposed voltages the rated DC voltage of the test setup was set to $\mathrm{U}_{\mathrm{DC}}=55 \mathrm{kV}$ due to the withstand level of the applied cable terminations. Further preliminary tests regarding the temperature rise of the described cable are described in [8].

With respect to worst case testing a LCC test procedure was chosen. The LCC test procedure was modified with respect to the load cycles due to the fact that the required temperature conditions can be achieved with a $5.5 \mathrm{~mm}$ thick cable insulation within cycles of $4 / 8 \mathrm{~h}$ (Table 4). For the long-term test an AC heating current of $\mathrm{I}=440 \mathrm{~A}$ was chosen resulting in a sheath temperature of $\vartheta=56{ }^{\circ} \mathrm{C}$ and a corresponding conductor temperature of $\vartheta=78^{\circ} \mathrm{C}$ (Figure 2). The joint mounted in the test loop shows a different temperature behaviour compared to the cable, with a greater thermal time constant and a lower maximum sheath temperature.

To provide the test voltage for the long-term test a DC voltage generator with an internal voltage divider capable of polarity reversals within $20 \mathrm{~s}$ was used. For the superimposed voltage tests a water resistor protects the DC generator, whereas the impulse generator was coupled to the test setup via a coupling capacitor $(\mathrm{C}=130 \mathrm{nF})$. A self-built universal voltage divider applicable for lightning impulses up to $\mathrm{U}_{\mathrm{LI}}=300 \mathrm{kV}$ and direct voltages up to $\mathrm{U}_{\mathrm{DC}}=200 \mathrm{kV}$ was used to measure the test voltage directly at the tested cable system (Figure 3). The resulting PQ test voltages for LCC are as follows:

$$
\begin{aligned}
\mathrm{U}_{\mathrm{DC}}=\mathrm{U}_{0} & =55 \mathrm{kV} \\
\mathrm{U}_{\mathrm{TP} 1} & =80 \mathrm{kV} \\
\mathrm{U}_{\mathrm{TP} 2} & =69 \mathrm{kV} \\
\mathrm{U}_{\mathrm{P} 2, \mathrm{O}} & =66 \mathrm{kV} \\
\mathrm{U}_{\mathrm{P} 1} & =116 \mathrm{kV}
\end{aligned}
$$

\begin{tabular}{|c|c|c|c|c|}
\hline No. & Test & No. of cycles/days & Polarity & $\begin{array}{c}\text { Test } \\
\text { voltage }\end{array}$ \\
\hline 1 & $\mathrm{LC}$ & $\begin{array}{l}10 \text { cycles, } 8 / 16 \mathrm{~h} \\
20 \text { cycles, } 4 / 8 \mathrm{~h}\end{array}$ & + & $\mathrm{U}_{\mathrm{TP} 1}$ \\
\hline 2 & $\mathrm{LC}$ & \begin{tabular}{|c|}
10 cycles, $8 / 16 \mathrm{~h}$ \\
20 cycles, $4 / 8 \mathrm{~h}$
\end{tabular} & - & UTP1 \\
\hline 3 & $\mathrm{LC}+\mathrm{PR}$ & $\begin{array}{c}40 \text { cycles, } 4 / 8 \mathrm{~h} \\
\text { every } 2^{\text {nd. }} 3 \times \text { PR }(4 \mathrm{~h})\end{array}$ & \pm & $\mathrm{U}_{\mathrm{TP} 2}$ \\
\hline 4 & S/IMP & --- & bipolar & $\mathrm{UP} 2, \mathrm{O}$ \\
\hline 5 & $\mathrm{HL}$ & 40 days & + & UTP1 \\
\hline 6 & HL & 40 days & - & $\mathrm{U}_{\mathrm{TP} 1}$ \\
\hline 7 & ZL & 120 days & - & $\mathrm{UTP}_{\mathrm{TP}}$ \\
\hline 8 & $\mathrm{LC}$ & 80 cycles, $4 / 8 \mathrm{~h}$ & + & UTP1 \\
\hline 9 & $\mathrm{LC}$ & 80 cycles, $4 / 8 \mathrm{~h}$ & - & $\mathrm{U}_{\mathrm{TP} 1}$ \\
\hline 10 & $\mathrm{LC}+\mathrm{PR}$ & $\begin{array}{c}40 \text { cycles, } 4 / 8 \mathrm{~h} \\
\text { every } 2^{\text {nd: }} 3 \times \text { PR }(4 \mathrm{~h})\end{array}$ & \pm & $\mathrm{U}_{\mathrm{TP} 2}$ \\
\hline 11 & S/IMP & --- & bipolar & $\mathrm{UP}_{2, \mathrm{O} / \mathrm{UP}_{\mathrm{P}}}$ \\
\hline
\end{tabular}

Table 4. Modified PQ test for MVDC LCC

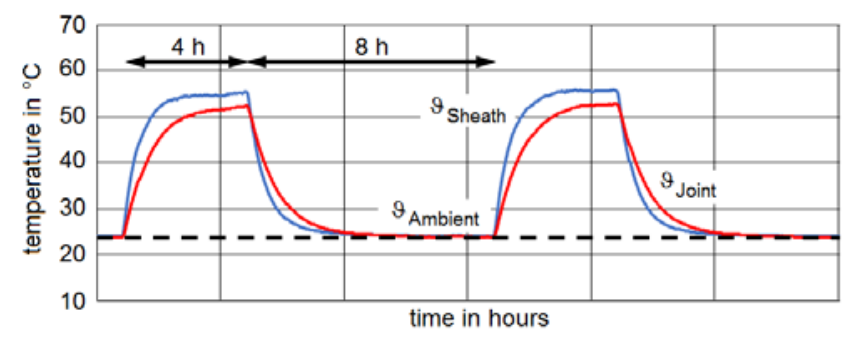

Figure 2. Modified load cycle test with 4 hours heating and 8 hours cooling (LC $4 / 8$ h)

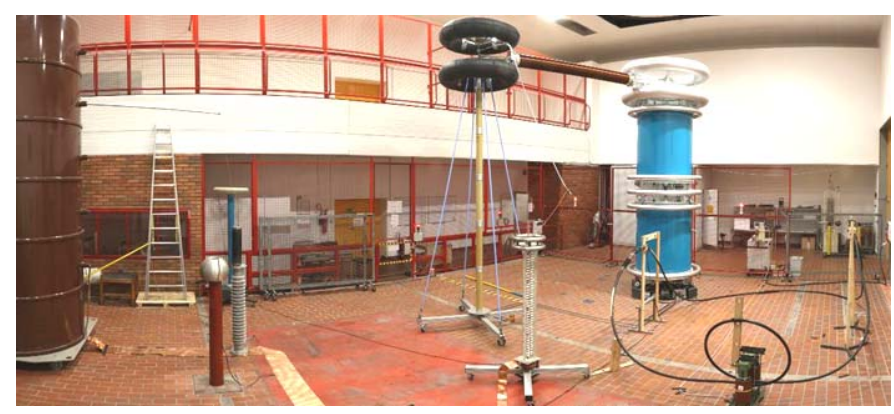

Figure 3. Arrangement for superimposed voltage test [8] 
During the ongoing PQ test the tests no. 1 - 10 of the modified PQ test for LCC were passed without any objection. A S/IMP test was performed additionally after test no. 3 with superimposed switching impulses to check for thermal/electrical aging of the cable loop. The test loop is currently (May 2019) going through test no. 11. This final S/IMP test with superimposed voltages (DC/SI, DC/LI) will be carried out to check the integrity of the insulation system.

\section{Discussion of PQ test for MVDC cable}

MVDC cables generally have the same design as HVDC cables. The main differences, however, are conductor crosssection, insulation thickness, insulation material and electric field stress during operation and testing. Therefore, some aspects and specifications of CIGRE TB 496 can be discussed and simplified for PQ test on MVDC cables. The testing of MVAC cable systems for DC operation should also be considered.

Test loop: A cable length of $10 \mathrm{~m}$ including accessories (two terminations and one joint) seem to be suitable for testing. The benefit is the saving of material and laboratory space.

Temperature time constant: The duration of the heating period and the cooling period at load cycles (LC) can be adjusted according to the thermal behaviour of the MVDC cable. The requirement of at least 2 hours at maximum conductor temperature and maximum temperature difference over the cable insulation must be met. Durations of $4 / 8$ hours or $6 / 6$ hours seem to be suitable for insulation thickness of about $5.5 \mathrm{~mm}$.

HV test equipment: The magnitude of test voltages is in the range below $100 \mathrm{kV}$ for DC and $140 \mathrm{kV}$ for SI/LI. For the mentioned voltage levels the application of blocking capacitors can be realized easily and the disadvantages of using blocking spark gaps can be avoided [13, 14]. Further on the direct measurement of the superimposed voltages with a universal divider or RC-divider is feasible without great effort.

Long duration voltage test: A design life of 40 years for extruded DC cables and the voltage-time characteristics based on the inverse power law model was chosen for the calculation of test duration. A life exponent of $\mathrm{N}=10$ and a test duration of 360 days lead to a test factor of 1.45 for the PQ test according to CIGRE TB 496. The mentioned life exponent of $\mathrm{N}=10$ was choosen by CIGRE WG members on conservative assumptions. There are some publications available that describe life exponents of up to $\mathrm{N}=26$ for DC material sheets tested with electric field stress of $\mathrm{E}>100 \mathrm{kV} / \mathrm{mm}[15,16]$. For a DC model cable a life exponent of $\mathrm{N}=18-24$ is described in [17]. In general, the life exponent for DC is considered to be greater than for $\mathrm{AC}$ and in this context a life exponent of $\mathrm{N}=12-15$ is stated for AC cables [18]. Table 5 shows the test factor for different test durations and life exponents and a design life of 40 years. In case of a life exponent of $\mathrm{N}=15$ the test factor is 1.40 for a test duration of 90 days and 1.44 for a test duration of 60 days. A lifetime exponent of $\mathrm{N}=13.7$ results from a test duration of 90 days and with the application of a test factor of 1.45 .

As a result, the long duration voltage test can be significantly shortened on the basis of a life exponent in the range of $\mathrm{N} \approx 15$. However, this depends on the intended number and type of test cycles and the dielectric time constant of the insulation material.
Table 5. Test factor for different test durations and life exponents

\begin{tabular}{|c|c|c|}
\hline $\begin{array}{c}\text { Design life, } \\
\text { test duration }\end{array}$ & Life exponent & Test factor \\
\hline \hline \multirow{2}{*}{$\begin{array}{c}40 \text { years, } \\
360 / 90 / 60 \text { days }\end{array}$} & 10.0 & $1.45 / 1.66 / 1.73$ \\
\cline { 2 - 3 } & 12.5 & $1.34 / 1.50 / 1.55$ \\
\cline { 2 - 3 } & 15.0 & $1.28 / 1.40 / 1.44$ \\
\hline
\end{tabular}

Duration of test cycles: The duration of each test should consider the necessary time to reach steady state electric field distribution in the insulation. The relevant dielectric time constant $\tau$ is given by volume resistivity $\rho$ and permittivity $\varepsilon$ where the resistivity resp. conductivity of the insulation material is strongly influenced by temperature and electric stress (1).

$$
\tau=\varepsilon_{0} \cdot \varepsilon_{\mathrm{r}} \cdot \rho(\mathrm{T}, \mathrm{E})
$$

CIGRE TB 496 mentioned the dielectric time constant with 5.5 - 430 hours at $20^{\circ} \mathrm{C}$ and less than $30 \mathrm{~min}$ at $90{ }^{\circ} \mathrm{C}$ and considers a time for stability of $10 \tau$ equal to $100 \%$ steady state for the duration of test cycles. In this context it should be noted that $95 \%$ of steady state is achieved after $3 \tau$ and $99 \%$ after $5 \tau$.

Figure 4 shows measurement results of volume resistivity for typical insulating materials at temperatures from $20^{\circ} \mathrm{C}$ up to $90{ }^{\circ} \mathrm{C}$ according to $[16,19]$. At $20^{\circ} \mathrm{C}$ a volume resistivity of about $5 \times 10^{15} \Omega \mathrm{m}$ for DC materials and about $1 \times 10^{14} \Omega \mathrm{m}$ for AC materials can be seen. The resistivity can change by 2 to 3 orders of magnitude in the before mentioned temperature range and resistivity of DC materials is about 100 times higher compared with resistivity of $\mathrm{AC}$ materials. This indicates that the dielectric time constant for testing MVAC cables for DC operation is much shorter than the figures given and considered by CIGRE TB 496 for the duration of test cycles. A further shortening can be observed taking $5 \tau(99 \%)$ into account for reaching steady state conditions instead of $10 \tau$. Therefore, the time for stability $(5 \tau)$ is about 3 hours at $20{ }^{\circ} \mathrm{C}$ and $2 \mathrm{~min}$ at $90{ }^{\circ} \mathrm{C}$. This confirms that the dielectric time constant is often short compared to temperature time constant [20].

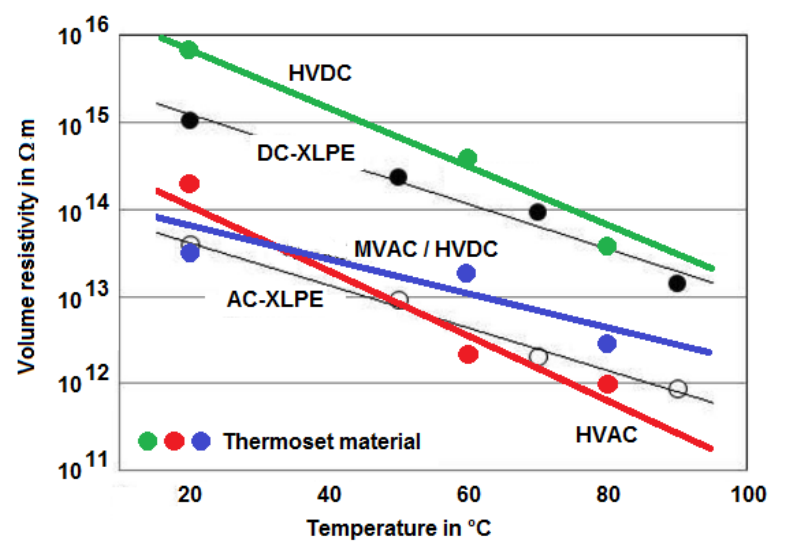

Figure 4. Volume resistivity of typical insulation materials at different temperatures $[16,19]$

As a result, the duration of the test cycles (LC, HL, ZL) can be significantly shortened on the basis of the above mentioned correlations. However, the resistivity of the insulating material under test must be taken into account. 
Accumulation of space charge: The space charge phenomena can distort the electric field distribution within the insulation bulk. Particularly after polarity reversal the presence of space charge can led to considerable electric field enhancement and can easily cause insulation breakdown. The injection of charge carriers occurs at the insulator/conductor interface when the applied electric field is higher than the threshold field for the specific insulation material. The threshold field depends on temperature and for PE/XLPE materials typical values of $\mathrm{E}=10 \mathrm{kV} / \mathrm{mm}$ at $25^{\circ} \mathrm{C}$ and $\mathrm{E}=3 \mathrm{kV} / \mathrm{mm}$ at $70^{\circ} \mathrm{C}$ are reported $[1,2]$. The space charge behaviour in polymeric materials is based on multiple factors, such as amplitude and duration of the applied electric field, temperature, temperature gradient in the insulation, electrode material, material properties, impurities and additives. For investigation of space charge behaviour material sheets or extruded cable insulation can be analysed with the nondestructive PEA method. The reduction of space charge accumulation is important for extruded DC cable technology and different measures are under investigation. However, it should be noted that in general the electric field stress for MVDC cables is about 2 times lower than for HVDC cables.

The PQ test shall verify in any case that the cable system is not affected by space charge phenomena. In this context, the polarity reversal during load cycles (LC $+\mathrm{PR}$ ), the duration of HL test cycle and S/IMP test are of particular importance.

Transient overvoltages: In case of a DC pole-to-ground fault in symmetrical monopolar VSC DC systems the healthy pole experiences a high transient overvoltage. The voltage stress applied is driven towards 2 p.u. of the nominal DC voltage and rise and decay time of such overvoltage is longer than what is typically tested in cable system qualification tests [21, 22]. Today, testing with a corresponding waveform is under discussion and further information from simulations and breakdown experiments is necessary to make a final decision on the modification of the PQ test procedure.

\section{Proposal for PQ test on MVDC cables}

The new proposal for the PQ test on MVDC cable systems follows the general principles of CIGRE TB 496 and consists of the long duration voltage test, which should have a minimum duration of 60 days, followed by the superimposed impulse voltage test (Table 6, Table 7). The sequence of tests for LCC and VSC are based on the experimental results described in chapter 6 and the discussions in chapter 7. A cable length of $10 \mathrm{~m}$ should be tested. The different tests and the additional requirements for MVDC can be summarized as follows:

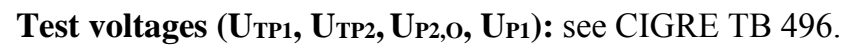

LC: test according to CIGRE TB 496, but the tested cable system is heated up for 6 hours followed by a cool down period of 6 hours ("12 hours" load cycle).

LC+PR: test according to CIGRE TB 496, but the polarity of the DC test voltage $U_{\text {TP2 }}$ is changed every 6 hours, whereas the tested cable system is heated up and cooled down with 6/6 hours cycles as described above. There is no PR at the end of the $5^{\text {th }}$ load cycle.

HL: test according to CIGRE TB 496.

S/IMP: test according to CIGRE TB 496.
The test with zero load (ZL) is not part of the PQ test for MVDC cables based on technical reasons and for saving time. A failure during ZL test is not expected, because the breakdown voltage of the insulation material at room temperature is much higher than at elevated temperature as it occurs during HL testing. In addition, all relevant space charge effects are covered by the other intended PQ tests. However, it is assumed that a $\mathrm{ZL}$ test is part of the development test.

Table 6. New PQ test for MVDC cable systems, LCC

\begin{tabular}{|c|c|c|c|c|}
\hline No. & Test & $\begin{array}{c}\text { No. of } \\
\text { cycles/days }\end{array}$ & Polarity & $\begin{array}{c}\text { Test } \\
\text { voltage }\end{array}$ \\
\hline$\overline{11}$ & $\overline{\mathrm{LC}}$ & 25 cycles, $6 / 6 \mathrm{~h}$ & + & UTP1 \\
\hline 2 & LC & 25 cycles, $6 / 6 \mathrm{~h}$ & - & $\mathrm{U}_{\mathrm{TP} 1}$ \\
\hline 3 & $\mathrm{LC}+\mathrm{PR}$ & 10 cycles & \pm & $\mathrm{U}_{\mathrm{TP} 2}$ \\
\hline 4 & $\mathrm{HL}$ & 15 days & + & $\mathrm{UTP}_{\mathrm{T} 1}$ \\
\hline 5 & $\mathrm{HL}$ & 15 days & - & UTP1 \\
\hline 6 & S/IMP & --- & bipolar & $\mathrm{UP} 2, \mathrm{O}_{\mathrm{O}} / \mathrm{U}_{\mathrm{P} 1}$ \\
\hline
\end{tabular}

Table 7. New PQ test for MVDC cable systems, VSC

\begin{tabular}{|c|c|c|c|c|}
\hline No. & Test & $\begin{array}{c}\text { No. of } \\
\text { cycles/days }\end{array}$ & Polarity & $\begin{array}{c}\text { Test } \\
\text { voltage }\end{array}$ \\
\hline \hline 1 & LC & 30 cycles, 6/6 h & + & UTP1 $_{T}$ \\
\hline 2 & LC & 30 cycles, 6/6 h & - & UTP1 \\
\hline 3 & HL & 15 days & + & UTP1 \\
\hline 4 & HL & 15 days & - & UTP1 \\
\hline 5 & S/IMP & --- & bipolar & UP2,O/UP1 \\
\hline
\end{tabular}

\section{Summary}

CIGRE TB 496 gives recommendations for a PQ test on extruded DC cable systems with rated voltage up to $500 \mathrm{kV}$, but do not consider the technical differences between HVDC and MVDC cables. MVDC cables generally have the same design as HVDC cables, but there are differences with respect to conductor cross-section, insulation thickness, insulation material and electric field stress during operation and testing. Therefore, an optimised PQ test is proposed for extruded MVDC cables taking into account their related thermal behaviour, dielectric time constant, life exponent and space charge behaviour.

The new proposal for the PQ test on MVDC cable systems follows the general principles of CIGRE TB 496 and consists of the long duration voltage test, which should have a minimum duration of 60 days, followed by the superimposed impulse voltage test. The test factor 1.45 and all test voltages are unchanged. However, for each test the number of cycles and duration was optimised for MVDC cables. The LC test consists of " 12 hours" cycles with 6 hour heating up and 6 hours for cooling down. The LC + PR test was optimized accordingly. HL test and S/IMP test are unchanged. The ZL test is not longer part of the PQ test due to technical reasons and for saving time.

The new PQ test for extruded MVDC cables will ensure the long-term performance of the complete cable system. The long duration voltage test of 60 days together with the S/IMP test will be equivalent to 40 years operation at rated voltage. 


\section{References}

[1] G. Mazzanti and M. Marzinotto, Extruded Cables for High-Voltage Direct-Current Transmission, IEEE Press, Wiley, USA, 2013.

[2] G. Chen, M. Hao, Z. Xu, A. Vaughan, J. Cao and H. Wang, "Review of High Voltage Direct Current Cables", CSEE Journal of Power and Energy Systems, Vol. 1, Issue 2, pp. 9-21, 2015.

[3] J. Brueggmann et al., "Prequalification Test of Extruded HVDC 525-kVUnderground Cables", CIGRE Session, Paris, France, Report B1-308, 2018.

[4] J. Yu et al., "Initial designs for ANGLE-DC project: challenges converting existing AC cable and overhead lone to DC operation", CIRED, Glasgow, UK, Report 974, 2017.

[5] Y. Liu, X. Cao and M. Fu, "The Upgrading Renovation of an Existing XLPE Cable Circuit by Conversion of AC Line to DC Operation", IEEE Transactions of Power Delivery, Vol. 32, No. 3, pp. 1321-1328, 2017.

[6] A. Burstein, V. Ćuk and E. Jong, "Determining Potential Capacity Gains when Repurposing MVAC Cables for DC Power Transportation", CIRED, Glasgow, UK, Report 142, 2017.

[7] A. Shekhar, M. Kontos, L. Ramírez-Elizondo, A. R. Mor and P. Bauer, "Grid capacity and efficiency enhancement by operating medium voltage AC cables as DC links with with modular multilevel converters", International Journal of Electrical Power and Energy Systems, Vol. 93, pp. 479-493, 2017.

[8] A. Buchner and U. Schichler, "Application of extruded MVAC Cables for DC Power Transmission”, JiCable '19, Versailles, France, 2019.

[9] CIGRE WG B1.32, "Recommendations for testing DC Extruded Cable Systems for Power Transmission at a Rated Voltage up to $500 \mathrm{kV}$ ", CIGRE Technical Brochure 496, 2012.

[10] M. Jeroense et al., "Fully qualified $640 \mathrm{kV}$ Underground Extruded DC Cable System", CIGRE Session, Paris, France, Report B1-309, 2018.

[11] CIGRE WG 21-01, "Recommendations for Testing DC extruded Cable Systems for power transmission at a rated voltage up to $250 \mathrm{kV}$ ", CIGRE Technical Brochure 219, 2003.

[12] IEC 62895, "High voltage direct current (HVDC) power transmission Cables with extruded insulation and their accessories for rated voltages up to $320 \mathrm{kV}$ for land application - Test methods and requirements", 2017.

[13] O. Pischler and U. Schichler, "Challenges resulting from the use of spark gaps for composite voltage tests", ICPADM, Xian, China, 2018.

[14] A. Voß and M. Gamlin, "Superimposed impulse voltage testing on extruded DC-Cables according to IEC CDV 62895", ISH, Buenos Aires, Argentina, Report 195, 2017.

[15] Y. Murata et al., "Development of High Voltage DC-XLPE Cable System”, SEI Technical Review, No. 76, pp. 55-62, 2013.

[16] Y. Ohki, "Development of an XLPE-Insulated Cable for LCC-HVDC Power Lines", IEEE Electrical Insulation Magazine, Vol. 34, No. 4 , pp. 62-65, 2018.

[17] K. Terashima, H. Suzuki, M. Hara and K. Watanabe, "Research and Development of $\pm 250 \mathrm{kV}$ DC XLPE Cable", IEEE Transactions on Power Delivery, Vol. 13, No. 1, pp. 7-16, 1998.

[18] E. Peschke and R. v. Olshausen, Cable Systems for High and Extra-High Voltage: Cable Design and Accessories - Dimensioning, Development and Testing, Wiley, Germany, 2000.

[19] R. N. Hampton, "Some of the Considerations for Materials Operating under High-Voltage, Direct Current Stress", IEEE Electrical Insulation Magazine, Vol. 24, No. 1, pp. 5-13, 2008.

[20] H. Ghorbani, M. Jeroense, C.-O. Olsson and M. Saltzer, "HVDC Cable Systems - Highlighting Extruded Technology", IEEE Transactions on Power Delivery, Vol. 29, No. 1, pp. 414-421, 2014.

[21] F. Palone, M. Marzinotto and L. Buono, "Temporary Overvoltage Mitigation in Symmetrical Monopole VSC-MMC HVDC Links", AEIT Int. Annual Conference, Cagliari, Italy, 2017.

[22] S. Mukherjee, M. Saltzer, Y.-J. Häfner and S. Nyberg, "Cable Overvoltage for MMC based VSC HVDC Systems: Interaction with Converters", CIGRE Int. Colloquium on HV Insulated Cables, New Delhi, India, 2017. 